\title{
Aclimatação de gengibre (Zingiber officinale Roscoe) e a relação com carboidratos endógenos
}

\author{
GIRARDI, C.G.; PESCADOR, R.* \\ Engenharia Ambiental, FURB - Universidade Regional de Blumenau - CEP: 89010-971, Blumenau-Brasil \\ *rosetep@furb.br
}

\begin{abstract}
RESUMO: O objetivo deste trabalho foi determinar as variações dos teores de açúcares solúveis totais e de reserva nas diferentes fases de desenvolvimento de mudas de gengibre. Foram avaliados os parâmetros de sobrevivência, teores de açúcares solúveis totais e de reserva na fase de micropropagação, aclimatação e cultivo em campo. A sobrevivência das plantas no processo de aclimatação aos 60 dias foi de $100 \%$, enquanto que as plantas em condições de campo apresentaram um índice de sobrevivência de $80 \%$ aos 60 dias de cultivo. Os teores médios de amido, no primeiro ano de cultivo, foram superiores nas plantas micropropagadas, tanto nas

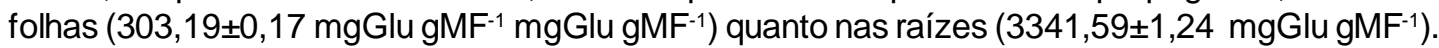
Foram observados altos teores médios de amido nos rizomas (164,91 $\pm 2,4$ mgGlu gMF-1 $^{-1}$ e gemas

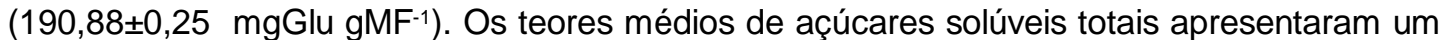


$\mathrm{mgGlu} \mathrm{gMF}^{-1}$ para folhas e raízes, respectivamente. Obteve-se um aumento nesses valores nas plantas aclimatadas em casa de vegetação, tanto nas folhas $\left(168,22 \pm 0,77\right.$ mgGlu gMF$\left.^{-1}\right)$ quanto nas raízes $\left(189,68 \pm 0,70 \mathrm{mgGlu} \mathrm{gMF}^{-1}\right)$, sendo superadas pelos teores médios de folhas e raízes

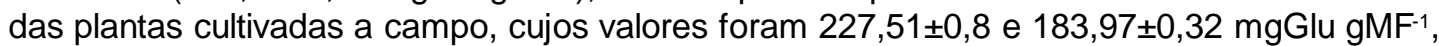
respectivamente. No segundo ciclo de cultivo observou-se um aumento nos teores médios de

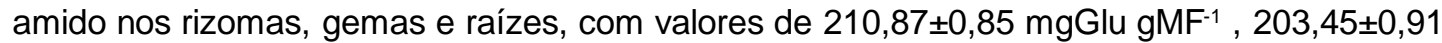

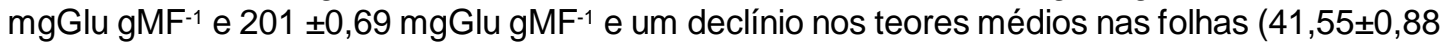
mgGlu gMF-1 $^{-1}$ ) com uma queda gradativa até os 240 dias de cultivo. Porém, em relação à quantidade de açúcares solúveis totais as folhas apresentaram-se com teores médios altos no período inicial, com um declínio ao longo do desenvolvimento em casa de vegetação. O oposto foi verificado para as raízes $\left(225,29 \pm 0,75 \mathrm{mgGlu} \mathrm{gMF}^{-1}\right)$, rizoma $\left(250,08 \pm 0,93 \mathrm{mgGlu} \mathrm{gMF}^{-1}\right)$ e gemas $(225,75 \pm 0,80$ mgGlu gMF $^{-1}$ ). Diante do alto índice de sobrevivência para as plantas aclimatadas e os teores mais elevados de açúcares solúveis totais e de reserva nas primeiras fases de cultivo, recomendase um período de aclimatação para garantir maior sobrevivência das plantas e garantir que realizem melhor alocação de reservas.
\end{abstract}

Palavras-chave: Zingiber officinale, micropropagação, aclimatação, açúcares totais, amido

\begin{abstract}
Acclimation of ginger (Zingiber officinale Roscoe) and its relation to endogenous carbohydrates. The aim of this work was to determine the variations in total soluble sugar and starch levels during the different development stages of ginger seedlings. Survival parameters, as well as total soluble sugar and starch levels, were evaluated during micropropagation, acclimation and field cultivation phases. The survival of plants was $100 \%$ after 60 days of acclimation, whereas under field conditions such value was $80 \%$ after the same period. In the first year of cultivation, mean starch levels were higher in micropropagated plants, both in leaves (303.19 \pm $\left.0.17 \mathrm{mgGlu} \mathrm{gFM}^{-1}\right)$ and in roots $\left(3341.59 \pm 1.24 \mathrm{mg} \mathrm{Glu} \mathrm{gFM}^{-1}\right)$. High mean starch levels were detected in rhizomes $\left(164.91 \pm 2.4 \mathrm{mg} \mathrm{Glu} \mathrm{gFM}^{-1}\right)$ and buds $\left(190.88 \pm 0.25 \mathrm{mgGlu} \mathrm{gMF}^{-1}\right)$. The mean levels of total soluble sugars were lower in plants in vitro: $86.56 \pm 0.55 \mathrm{mgGlu} \mathrm{gFM}^{-1}$ and $94.26 \pm 0.40 \mathrm{mgGlu} \mathrm{gFM}^{-1}$ in leaves and roots, respectively. Higher values were obtained for plants acclimatized in greenhouse, both in leaves $\left(168.22 \pm 0.77 \mathrm{mgGlu} \mathrm{gFM}^{-1}\right)$ and roots $(189.68 \pm 0.70$
\end{abstract}

Recebido para publicação em 27/12/2008

Aceito para publicação em 24/07/2009

Rev. Bras. PI. Med., Botucatu, v.12, n.1, p.62-72, 2010. 
mgGlu $\mathrm{gFM}^{-1}$ ); these values were inferior to those detected in leaves and roots of plants grown in the field, which were $227.51 \pm 0.8$ and $183.97 \pm 0.32 \mathrm{mgGlu} \mathrm{gFM}^{-1}$, respectively. In the second cultivation cycle, mean starch levels in rhizomes, buds and roots increased to $210.87 \pm 0.85$ mgGlu gFM-1, $203.45 \pm 0.91 \mathrm{mgGlu} \mathrm{gFM}^{-1}$ and $201 \pm 0.69 \mathrm{mgGlu} \mathrm{gFM}^{-1}$, respectively, whereas in leaves these values progressively decreased $\left(41.55 \pm 0.88 \mathrm{mgGlu} \mathrm{gFM}^{-1}\right)$ until 240 days of cultivation. However, leaves presented high mean total soluble sugar levels in the initial period, with a posterior decline over the development in greenhouse. The opposite was observed in roots $\left(225.29 \pm 0.75 \mathrm{mgGlu} \mathrm{gFM}^{-1}\right)$, rhizomes $\left(250.08 \pm 0.93 \mathrm{mgGlu} \mathrm{gFM}^{-1}\right)$ and buds $(225.75 \pm 0.80$ $\mathrm{mgGlu}_{\mathrm{gFM}}{ }^{-1}$ ). Based on the high survival rate of acclimatized plants and the higher levels of total soluble sugars and starch in early stages of cultivation, acclimation is recommended to assure higher plant survival and reserve allocation.

Key words: Zingiber officinale, micropropagation, acclimation, total sugars, starch

\section{INTRODUÇÃO}

O gengibre (Zingiber officinale Roscoe) pertence à família Zingiberaceae e a importância está nas propriedades terapêuticas. Tem sido empregado há milhares de anos na Ásia para alívio de várias enfermidades como artrites, reumatismo, dores musculares, febre, gripe, cólicas e bronquites (Dedov et al., 2002).

O sistema de propagação vegetativa convencional do gengibre apresenta sérios problemas relacionados à qualidade fitossanitária, dentre eles tem-se a disseminação de doenças a cada ciclo da cultura em decorrência de patógenos do solo, tendo como conseqüência a destruição total das plantações devido à disseminação rápida, principalmente de espécies de fungos como Fusarium oxyporium, Armillariella mellea e Sclerotium rolfsii; espécies nematóides como Meloidogyne incognitae M. Javanica e ainda de bactérias; como por exemplo, Ralstonia solanacearum e Erwinia sp. (Arimura, 2002).

A propagação do gengibre por meio do sistema in vitro é apontada como técnica importante na obtenção de um grande número de mudas em curto espaço de tempo e isentas de patógenos, conferindo a estas, qualidade fitossanitária (Mercier \& Kerbauy, 1997).

Exemplos destes protocolos podem ser conferidos nos trabalhos de Samsudeen et al. (2000), Khatun et al. (2003) e Debiasi et al. (2004), cujos autores obtiveram êxito na obtenção de alta taxa de regeneração de mudas de gengibre isenta de patógenos. Mais recentemente Girardi et al. (2007) obtiveram a fomação de 4 brotos por explante, em trinta dias de cultivo in vitro, enfatizando a importância desta técnica.

O procedimento de aclimatação das plantas, segundo Hoffmann (2002), consiste na adaptação das plantas às condições ambientais após remoção das condições in vitro, antes do transplante para o local definitivo, método que por vezes acarreta baixo índice de sobrevivência das mudas em detrimento de baixa taxa fotossintética, deixando o vegetal não completamente autotrófico (Campostrini \& Otoni, 1996).
Durante esta etapa o armazenamento de carboidratos se torna necessário Já que participam de uma série de processos vitais, como desenvolvimento de plântulas, diferenciação radicular e foliar e senescência (Leon \& Sheen, 2003). Além de processos como o controle da formação das raízes e caule em grande número de espécies (Wilson, 1998) e formação de tubérculos como, por exemplo, em Solanum tuberosum (Müller-Röber et al., 1992). Os carboidratos também estão envolvidos no processo que antecedem a divisão celular, possivelmente servindo como fonte de energia para as células, ou fornecer esqueletos de carbono para a síntese de outros compostos necessários para a célula (Taiz \& Zeiger, 2004).

Contudo, as reservas de carboidratos variam qualitativa e quantitativamente dentro das espécies, órgãos, tecidos e células, bem como ao longo do dia, e nas diferentes estações anuais (Lewis, 1984).

Diante disso, este trabalho tem por objetivo verificar a alocação de fotoassimilados nas diferentes partes das mudas de gengibre durante a multiplicação in vitro, na fase de aclimatação e no campo, para identificação do período de sua maior demanda, visto que teores de açúcares solúveis e de reserva podem ser indicativos de qualidade das mudas, para melhorar o crescimento e desenvolvimento na aclimatação e no campo.

\section{MATERIAL E MÉTODO}

\section{Cultivo in vitro}

Para o estabelecimento das culturas in vitro, utilizou-se gemas de rizoma de gengibre, submetidas ao processo de assepsia que consistiu de imersão por 20 minutos em solução comercial QBOA de hipoclorito de sódio com $2,5 \%$ de cloro ativo, imersão por 2 minutos em solução alcoólica $70 \%$, seguido de três lavagens sucessivas em água estéril. As gemas foram isoladas e inoculadas em tubos de ensaio 
contendo meio de cultura MS (Murashige \& Skoog, 1962) suplementado com sacarose $\left(30 \mathrm{~g} \mathrm{~L}^{-1}\right)$ e 20 $\mu \mathrm{mol} \mathrm{L}^{-1}$ de BAP (6-benzilaminopurina), o pH ajustado para 5,8 e semi-solidificado com Ágar (7g L-1).

As culturas foram mantidas em ambiente apresentando temperatura de $27 \pm 2^{\circ} \mathrm{C}$, fotoperíodo de 16 horas de luz a uma intensidade luminosa de 50 $\mathrm{mm}^{-2} \mathrm{~s}^{-1}$. Após 30 dias de cultivo in vitro foram transferidas para vidros de $350 \mathrm{~mL}$ contendo a mesma formulação de meio de cultura anterior e mantidas sob as mesmas condições descritas anteriormente. Aos 30 dias de cultivo as mudas que apresentavam uma altura média de $3,5 \mathrm{~cm}$ foram utilizadas na aclimatação e algumas foram colhidas amostras para quantificação dos carboidratos.

\section{Aclimatação em casa de vegetação}

Para a aclimatação 200 plantas obtidas do cultivo in vitro foram transferidas para casa de vegetação e colocadas em copos plásticos $(200 \mathrm{~mL})$ contendo substrato constituído por casca de arroz carbonizado + plantmax ${ }^{\circledR}+$ areia na proporção de (1:1:1), previamente esterilizado em autoclave, durante 1 hora a $121^{\circ} \mathrm{C}$. As condições ambientais de cultivo em casa de veaetacão foram: umidade relativa do ar de redução da incidência solar com utilização de sombrites por um período de 30 dias. Nesta etapa, aos 60 dias de cultivo foi feita a segunda coleta para quantificação de carboidratos.

\section{Aclimatação em casa de vegetação (2 Ano de cultivo) \\ Após 60 dias de cultivo em casa de} vegetação, 100 plantas foram transferidas para vaso, tamanho número 1 contendo o mesmo substrato, já citado, por um período de 240 dias.

\section{Aclimatação em campo}

Um total de 100 mudas foi transferido para condições de campo para comparação de índices de sobrevivência, altura, número de brotos e teores de açúcares e amido entre as condições de campo e casa de vegetação. As condições de campo consistiram formação de mulchões com $10 \mathrm{~cm}$ de altura previamente adubados com $100 \mathrm{Kg} \mathrm{ha}^{-1}$ (NPK 11-7-35). Nas amostras das mudas mantidas em casa de vegetação e em condições de campo, após 60 dias de cultivo, também foram quantificados os teores de carboidratos.

O fluxograma completo do material e métodos, com todas as fases de cultivo, é mostrado
A

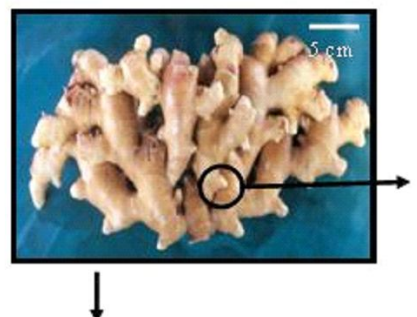

Gemas assepsia:

20 min Hipoclorito de sódio com $2,5 \%$ de cloro ativo 2 min Álcool (70\%)



$\mathrm{MS}+\operatorname{BAP}\left(200 \mu \mathrm{Mol} \mathrm{L}^{-1}\right)$

Sacarose $\left(30 \mathrm{~g} \mathrm{~L}^{-1}\right)$

Ágar $\left(7 \mathrm{~g} \mathrm{~L}^{-1}\right)$ 30 dias

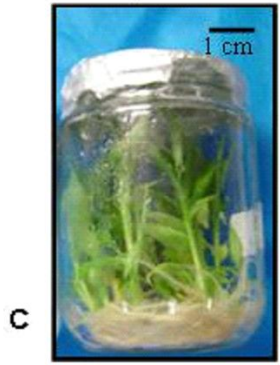

Casca de arroz carbonizada + areia + Plantmax (1:1:1)

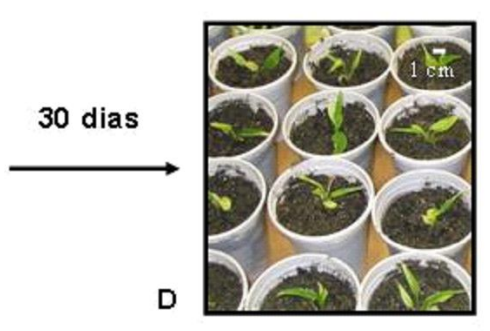

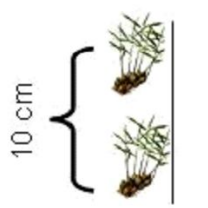
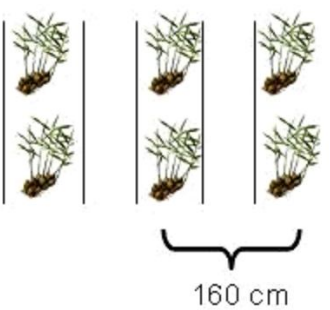

G
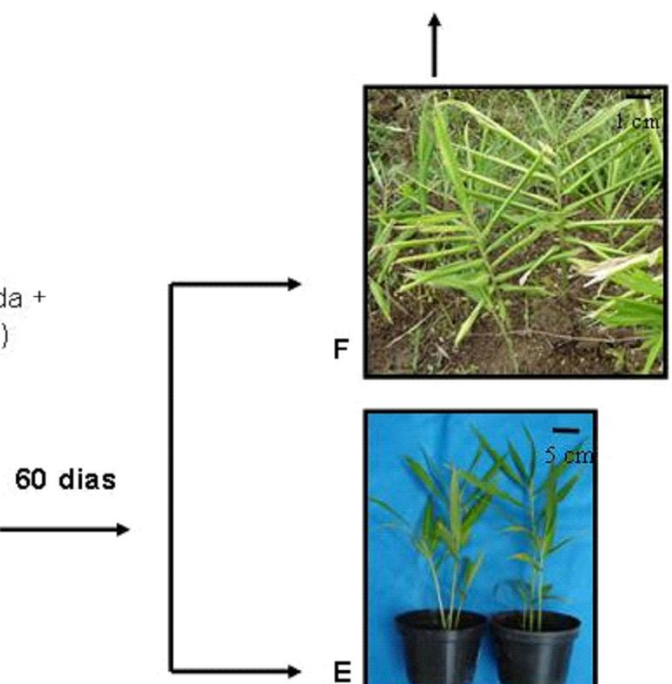

FIGURA 1 (A-E). Etapas do estabelecimento do cultivo in vitro, aclimatação e cultivo a campo, sendo que . Em Aestabelecimento in vitro; B e C- fase de multiplicação, alongamento e enraizamento; D- transferência para condições de casa de vegetação; E- transferência das mudas para vasos tamanho 1, onde foram mantidas por 240 dias; F-transferência das mudas para condições de campo; e G- representação da disposição das mudas em condições de campo. 


\section{Extração e quantificação dos teores de amido e açúcares solúveis totais}

\section{Açúcares Solúveis Totais (AST)}

Para a extração e quantificação dos AST foi utilizado o método descrito por Vaz et al. (1998), no qual foram tomadas amostras do material mantido in vitro e nos diferentes processos de aclimatação (1ㅇ e 2o ano de cultivo), que correspondem as etapas $C$, $\mathrm{D}, \mathrm{E}$ e $\mathrm{F}$ da Figura 1. Cerca de $1 \mathrm{~g}$ de massa fresca, foram maceradas em graal com pistilo e, em seguida, submetidas a uma extração tripla por fervura em etanol $80 \%$ durante 5 minutos.

Os extratos foram centrifugados a $3200 \mathrm{~g}$, a $20^{\circ} \mathrm{C}$, por 10 minutos e filtrados em microfibra de vidro. Da combinação dos três extratos alcoólicos obteve-se uma porção correspondente à fração de açúcares solúveis, sendo o volume ajustado com solução alcoólica, de acordo com metodologia proposta por Pollock \& Jones (1979). Na quantificação colorimétrica dos AST a $490 \mathrm{~nm}$, utilizou-se o método fenol-sulfúrico descrito por Dubois et al. (1956).

\section{Determinação de amido}

A cada resíduo sólido das extrações de açúcares totais, adicionou-se $2 \mathrm{~mL}$ de água destilada gelada e 2,6 $\mathrm{mL}$ de ácido perclórico (52\%), mantidos por 15 minutos em banho de gelo e agitados ocasionalmente com bastão de vidro. Em seguida, adicionou-se mais $4 \mathrm{~mL}$ de água deionizada, agitou-se e centrifugou-se posteriormente em $3.200 \mathrm{~g}$, por 15 minutos, conforme proposto por McCready et al. (1950).

O resíduo sólido foi submetido a mais duas extrações com $1 \mathrm{~mL}$ de água e $1,3 \mathrm{~mL}$ de ácido perclórico (52\%). O volume final das 3 extrações foi filtrado em microfibra de vidro e deferido para $10 \mathrm{~mL}$. $\mathrm{Na}$ determinação colorimétrica de amido a $490 \mathrm{~nm}$, utilizou-se o método fenol-sulfúrico descrito por Dubois et al. (1956).

\section{RESULTADOE DISCUSSÃO}

\section{Cultivo in vitro}

No presente estudo, o número médio de mudas de gengibre obtidos, no cultivo in vitro, foi o mesmo obtido por Girardi et al. (2007), ou seja, 4 brotos por explante, aos trinta dias de cultivo com altura média de $3,5 \mathrm{~cm}$. Resultados similares foram mostrados por Debiasi et al. (2004), cujos autores ainda verificaram que quando as mudas eram retiradas da suplementação de reguladores vegetais, AIA e BAP, a altura aumentava e emissão de brotos diminuía.

\section{Aclimatação em casa de vegetação}

No processo de aclimatação, verificou-se aos
60 dias, $80 \%$ de sobrevivência das mudas de gengibre oriundas do cultivo in vitro, apresentando altura média de $7 \mathrm{~cm}$, números médios de 2 proliferações por muda e 8 folhas.

No trabalho de Girardi et al. (2007), foram obtidas $100 \%$ de mudas sobreviventes independente das diferentes composições de substratos utilizadas. Percentual de sobrevivência de $80 \%$ foi obtido anteriormente por Babu et al. (1992), para mudas micropropagadas de gengibre quando aclimatadas em substratos do tipo solo + areia (1:1). Para Bhagyalakshimi \& Sing (1988), o índice de sobrevivência foi de $90 \%$, utilizando como substrato uma mistura de solo, substrato orgânico vegetal e areia, e Debiasi et al. (2004) aclimataram gengibre em substrato de casca de arroz carbonizada e areia (1:1), sob redução solar de $50 \%$, por um período de 60 dias e obtiveram $95 \%$ de sobrevivência das mudas.

A combinação de substratos utilizados neste trabalho influenciou a elevada porcentagem de sobrevivência das mudas, pois, os substratos exercem influência significativa na arquitetura do sistema radicular e nas associações biológicas com o meio, influenciando o estado nutricional das plantas e a translocação de água no sistema solo-plantaatmosfera (Coutinho \& Carvalho, 1983).

As características do substrato como o elevado espaço de aeração associado à elevada capacidade de retenção de água são fatores fundamentais durante a aclimatação (Calvete, 1998). Embora o substrato possa ser formado por um único material, dificilmente será encontrado um que suprirá todas as características positivas necessárias. Por essa razão, os substratos em geral representam a mistura de dois ou mais componentes, como no presente trabalho, sendo que um destes, o condicionador de substratos, irá promover a correção das características de forma a otimizar as condições de uso (Kämpf, 2000).

De acordo com Hoffmann et al. (1996), um bom substrato deve ser firme e denso o suficiente para dar sustentação até o enraizamento; não encolher ou expandir com a variação da umidade; reter água em quantidade adequada; e ser suficientemente poroso para permitir a drenagem da água e a aeração. Deve também, estar livre de invasoras, nematóides ou outros patógenos; não apresentar níveis excessivos de salinidade e permitir a esterilização por vapor.

Diante disso, a composição do substrato utilizada e manutenção em casa de vegetação no presente trabalho auxiliaram na taxa de sobrevivência das mudas de gengibre em decorrência da textura e aeração do substrato, controle da luminosidade e temperatura, fatores fundamentais para o bom crescimento e desenvolvimento para permitir um melhor desempenho em condições de campo. 


\section{de cultivo) \\ Aclimatação em casa de vegetação (2ำ Ano}

As mudas mantidas em casa de vegetação durante $\circ 2^{\circ}$ ano de cultivo mostraram-se com um índice de sobrevivência de 100\%, com média de altura de $24 \mathrm{~cm}$, número médio de 12 folhas e média de 3 proliferações. Resultado este que nos remete ao fato de que a manutenção das mudas na fase de aclimatação em condições de casa de vegetação proporcionou maiores médias em altura, número médio de folhas e de proliferações.

Tal desempenho pode estar associado às características desses substratos, que proporcionaram condições favoráveis para o melhor desenvolvimento das mudas, e ao monitoramento e controle do ambiente interno em casa de vegetação. A manutenção das plantas em condições de casa de vegetação proporcionou às mudas atingirem médias ótimas em todos os parâmetros avaliados. Segundo Costa (2001), em condições de casa de vegetação é possível proporcionar maior controle em relação à temperatura, umidade relativa, radiação solar, nível de $\mathrm{CO}_{2}$, sombreamento artificial e nutrição de plantas.

Durante o cultivo in vitro, as plântulas crescem sob condições muito especiais dentro dos frascos, com umidade relativa do ar elevada e radiação reduzida quando comparado ao cultivo tradicional. Além disso, pelo fato de estarem em frascos fechados visando proteção microbiológica, não há turbulências provocadas pelo fluxo de ar, tampouco facilidades na entrada de $\mathrm{CO}_{2}$ e saída de gases produzidos pela planta. O meio de cultura é freqüentemente suplementado por açúcares como fonte de carbono e outras fontes de energia, que provocam considerável decréscimo do potencial hídrico do meio. Além disso, há o fornecimento de grandes quantidades de reguladores de crescimento.

Estas condições resultam na formação de plântulas com anormalidades morfológicas, anatômicas e fisiológicas. Assim, depois de transferidas para a condição ex-vitro, as plantas tem que se adaptarem as novas condições, onde a radiação é muito maior e a umidade relativa do ar muito menor. Mesmo sob potencial hídrico do substrato maior que do meio onde estavam às plântulas podem rapidamente murchar se a perda de água em excesso pelas folhas não for impedida. Além disso, o fornecimento suplementar de água pode não ser efetivo devido à baixa condutividade hidráulica das conexões dos vasos das raízes e caule. Muitas plântulas morrem durante este período (Pospisilová et al., 1999).

Por esta razão, após o transplante para as condições externas, as plântulas necessitam usualmente de algumas semanas de aclimatação sob decréscimo gradual na umidade relativa do ar, e conforme observado neste trabalho, quanto maior este período em casa de vegetação, melhor o desempenho das mudas posteriormente em campo.

\section{Aclimatação em campo}

As mudas em condições de campo apresentaram um índice de sobrevivência de $80 \%$ aos 60 dias de cultivo, apresentaram altura média de de $25 \mathrm{~cm}$, números médios 5 proliferações e 11 folhas por planta.

Os índices de sobrevivência observados na aclimatação em condições de campo foram semelhantes aos obtidos durante a aclimatação em casa de vegetação, contudo foram menores. Portanto, mesmo que as mudas tenham passado pelo período de aclimatação em condições de casa de vegetação para facilitar o seu desempenho e sobrevivência em campo, os estresses ocasionados pela exposição direta da luz solar no campo, provavelmente, ocasionariam médias menores nos parâmetros observados.

Segundo Wardle et al. (1983), aclimatação compreende o período entre o transplante das plantas produzidas in vitro e o total estabelecimento ex vitro. Além de serem pouco eficientes fotossinteticamente, as folhas das plantas cultivadas in vitro possuem menor quantidade de ceras epicuticulares do que as plantas crescidas em casa de vegetação ou no campo e, associadas a pouca funcionalidade dos estômatos e à fraca conexão com o sistema vascular, tornamnas sensíveis a grandes perdas de água por transpiração, podendo levá-las à morte (Sciutti \& Morini, 1993; Ross-Karsten et al., 1998; Pospísilová et al., 1999).

O desempenho das mudas que passaram por esta fase de aclimatação e apresentaram em campo um desempenho inferior nos parâmetros observados, como índice de sobrevivência, provavelmente está relacionado ao padrão de crescimento das plantas. Isso se deve ao fato de que, ao sofrer mudança abrupta de ambiente, normalmente as plantas apresentam uma parada ou redução do crescimento até que se adaptem às novas condições, podendo levar de dias a semanas até que retornem ao crescimento (Pereira \& Fortes, 2004; Pereira et. al., 2001). Assim, a redução de perdas por morte, associada ao rápido crescimento de mudas tanto no período de aclimatação quanto em campo são fatores que podem contribuir significativamente para que mudas micropropagadas cheguem ao setor produtivo de forma mais rápida e barata (Pereira \& Fortes, 2004).

Para tanto, a escolha adequada de substratos para cada espécie é de fundamental importância (Schmitz et al., 2002), assim como aperfeiçoamento de técnicas durante o período de aclimatação e em campo. Alguns estudos sugerem a transferência das mudas obtidas do cultivo in vitro diretamente para as condições de campo, como verificado por Khatun et al. (2003), cujos autores obtiveram $100 \%$ de 
sobrevivência em mudas micropropagadas de gengibre estabelecidas diretamente no campo. No entanto, menores porcentagens de sobrevivência podem ser encontradas quando se usa esta técnica, como encontrado nos estudos de Hosoki \& Sagawa (1977), onde os índices de sobrevivência obtidos foram de 60 a $70 \%$, ao estabelecerem mudas diretamente no campo. Portanto, a importância da presença ou ausência deste período de aclimatação para as mudas de gengibre micropropagadas deve ser estudado, pois as mudas estabelecidas diretamente em condições de campo podem se apresentar mais vulneráveis, tendo em vista um período maior de avaliação também para a produção das mudas.

\section{Teores de amido e açúcares solúveis totais na micropropagação e nas diferentes fases de aclimatação}

\section{Primeiro ciclo de cultivo}

O conteúdo de carboidrato solúvel total variou nas diferentes fases e ou etapas da propagação do gengibre, sendo que os teores médios de amido foram superiores nas plantas provenientes de micropropagação in vitro, tanto nas folhas

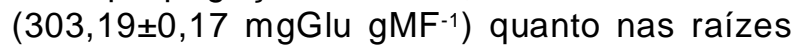
$(3341,59 \pm 1,24$ mgGlu gMF-1), quando comparadas com as mudas aclimatadas em casa de vegetação e cultivadas em condições de campo.

As mudas cultivadas em condições de campo apresentaram teores médios de amido de $176,66 \pm 0,4$ nas folhas e $91,58 \pm 0,22$ mgGlu gMF$^{-1}$ nas raízes, mais elevados em comparação com as plantas aclimatadas em casa de vegetação, cujas folhas e raízes apresentaram teores médios de amido de $84,56 \pm 0,20$ e $138,37 \pm 0,21 \mathrm{mgGlu}_{\mathrm{gMF}}^{-1}$, respectivamente (Tabela 1 ).

O fato das plantas micropropagadas apresentarem maiores teores médios de amido, tanto nas raízes quanto nas folhas, ocorre devido às plantas micropropagadas não serem completamente autotróficas. Wardle et al. (1983) ressaltam que o acúmulo de grandes reservas de amido nas folhas de plantas cultivadas in vitro é necessário para a sobrevivência das plantas durante as primeiras semanas ex vitro, que seria o período de aclimatação. Além do aparelho fotossintético ainda ser ineficiente, as folhas destas plantas também possuem menor quantidade de cera epicutilar do que as plantas crescidas em casa de vegetação, um dos fatos responsáveis pela transpiração excessiva que acaba auxiliando no dessecamento e murchamento da folhas no transplantio (Campostrini \& Otoni, 1996). O amido suporta o metabolismo e crescimento no escuro,

TABELA 1. Teores médios de amido (mgGlu gMF-1) em plantas de gengibre micropropagadas (30 dias), aclimatadas em casa de vegetação (60 dias) e cultivadas no campo (60 dias).

\begin{tabular}{lcccc}
\hline \multicolumn{1}{c}{ Material } & Foores médios de amido $\left(\mathbf{m g G l u}\right.$ gMF $\left.^{-1}\right)$ & & \\
& $303,19 \pm 0,17$ & $341,59 \pm 1,24$ & - & Raízes \\
\hline Plantas in vitro (30 dias) & Rizomas & Gemas \\
Plantas aclimatadas em C.V.* (60 dias) & $84,56 \pm 0,20$ & $138,37 \pm 0,21$ & - & - \\
Plantas cultivadas em campo (60 dias) & $176,66 \pm 0,4$ & $91,58 \pm 0,22$ & $164,91 \pm 2,4$ & $190,88 \pm 0,25$ \\
\hline
\end{tabular}

* C.V. - Casa de Vegetação

quando a fotossíntese não é possível, por isso mantém alto teor de amido nas folhas, como observado nas plantas in vitro (Zeemann et al., 2004). As plantas passam de estado heterotrófico, na qual dependem do suprimento exógeno de energia (fonte de açúcar no meio, no caso sacarose) e alta diponibilidade de nutrientes, para estado autotrófico, no qual precisam realizar fotosíntese e incrementar rapidamente a absorção de nutrientes para sobreviver (Grattapaglia \& Machado, 1990).

Os teores médios de amido nos rizomas e gemas foram avaliados apenas nas plantas cultivadas em campo, por ausência dos mesmos nos outros cultivos. Foram observados altos teores médios de amido nos rizomas $\left(164,91 \pm 2,4 \mathrm{mgGlu}_{\mathrm{gMF}}^{-1}\right)$ e gemas $\left(190,88 \pm 0,25\right.$ mgGlu gMF-1) em relação as $^{-1}$ outras partes vegetais observadas, valores esperados porém, quando comparadas as plantas mantldas em casa de vegetação, onde as folhas apresentaram maior teor médio de amido $\left(176,66 \pm 0,4\right.$ mgGlu gMF-1 $\left.^{-1}\right)$. Este comportamento foi relatado para espécies como videira (Hidalgo, 1993) e pessegueiro (Borba et al., 2005), onde os altos teores de amido nas folhas, parece ser importante para processos que demandam energia como crescimento de ramos, florescimento e frutificação. No caso do gengibre, que se trata de planta perene cuja parte aérea senesce ao final do período de crescimento anual, essas reservas são utilizadas principalmente para a retomada do crescimento após período de dormência . 
Em relação às plantas aclimatadas em casa de vegetação, sabe-se que esta fase se caracteriza por ser crítica para as plantas. É um período de estresse, o qual leva a transpiração excessiva, redução de número de estômatos, mal funcionamento no mecanismo de abertura e fechamento estomático (Campostrini \& Otoni, 1996), fatores estes também intensificados por sinais ambientais como luz, temperatura e umidade (Almeida \& Pereira, 2004).

Fatores como luz água e temperatura, podem influenciar muito o metabolismo das plantas e levá-las ao estresse hídrico, interferindo nos teores endógenos de carboidratos (Kramer \& Boyer, 1995). Isto porque, em condições de estresse hídrico, o amido é degradado nos tecidos que o acumulam, havendo redução na quantidade do mesmo e em conseqüência, da atividade da amilase. O menor teor de amido obtido na fase de aclimatação pode ser atribuído ao estresse ao qual a planta é submetida durante a transferência (Chaves-Filho \& StacciariniSeraphin, 2001).

A análise da quantidade média de açúcares solúveis totais está apresentada na Tabela 2, nas qual observa-se os teores médios de açúcares solúveis totais apresentaram um decréscimo nas plantas in vitro com valores médios de 86,56 $\pm 0,55$ mgGlu gMF-1 $^{-1}$ e 94,26 $\pm 0,40 \mathrm{mgGlu} \mathrm{gMF}^{-1}$ para folhas e raízes, respectivamente. Obteve-se aumento nesse valores nas plantas aclimatadas em casa de vegetação tanto para

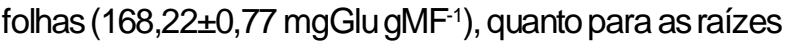
$\left(189,68 \pm 0,70\right.$ mgGlu gMF$\left.^{-1}\right)$, sendo superadas somente pelos teores médios de folhas e raízes das plantas cultivadas a campo, cujos valores foram $227,51 \pm 0,8 \mathrm{e}$ $183,97 \pm 0,32$ mgGlu gMF-1, $^{-1}$, respectivamente.

Para os AST, os teores médios nos rizomas e gemas também só foram avaliados nas plantas cultivadas em campo, por ausência dos mesmos nos outros cultivos. As gemas apresentaram-se com maiores teores médios de açúcares solúveis totais $\left(167,22 \pm 0,22\right.$ mgGlu gMF-1) comparativamente aos $^{-1}$ teores médios contidos no rizoma $(191,03 \pm 0,29$ mgGlu gMF-1),

Observou-se redução nos teores de AST nas plantas na fase in vitro e aumento desses valores nas fases de aclimatação em casa de vegetação e nas plantas cultivadas no campo, indicando que há relação entre açúcares e amido nas plantas de gengibre nas diferentes fases de desenvolvimento, comprovado pelas avaliações de quantidade de açúcares e amido. Davies (1984) observou redução nos níveis de açúcares totais em tubérculos de Solanum tuberosum em desenvolvimento, indicando aumento na taxa de síntese de amido. O mesmo foi relatado por Tjaden et al. (1998) e Pastorini et al. (2003), mostrando que níveis reduzidos de amido podem ser correlacionados com o aumento no conteúdo de AST.

Sabe-se que, na maioria da plantas, a sacarose é o principal açúcar exportado dos locais de síntese (folhas) para as regiões de consumo (caule, gemas, raízes e órgãos reprodutivos) onde será utilizada para o crescimento e/ou armazenamento (Chaves-Filho \& Stacciarini-Seraphin, 2001). Uma vez translocada a locais não fotossintetizantes, a sacarose é rapidamente convertida em frutose e glicose por enzimas invertases.

Durante o dia, a taxa de fotossíntese de amido nos cloroplastos deve ser coordenada com a síntese de sacarose no citoplasma. As trioses fosfato (gliceraldeído-3-fosfato e diidroxiacetona fosfato) produzidas no cloroplasto pelo ciclo de Calvin podem ser usadas tanto para a síntese de amido quanto de sacarose (Taiz \& Zeiger, 2004). Devido a isto, supõese que este declínio de AST no decorrer do desenvolvimento paralelo a este aumento no teor médio de amido, remete a constatar que possivelmente os teores de amido e açúcares estão correlacionados e, pelo fato de se saber que as sínteses de amido e sacarose são reações competitivas, supõe-se que pode haver altos teores de sacarose nas mudas de gengibre, apesar de não avaliado no presente trabalho, tendo em vista que houve inversão nas quantidades de teores médios durante as diferentes fases de cultivo.

As gemas e rizomas das plantas cultivadas a campo apresentaram-se com maiores teores

TABELA 2. Teores médios de açúcares solúveis totais $\left(\mathrm{mgGlu} \mathrm{gMF}^{-1}\right)$ em plantas de gengibre micropropagadas (30 dias), aclimatadas em casa de vegetação (60 dias) e cultivadas no campo (60 dias).

Teores médios de açúcares solúveis totais $\left(\mathrm{mgGlu}_{\mathrm{gMF}}{ }^{-1}\right.$ )

\begin{tabular}{lcccc}
\multicolumn{1}{c}{ Material } & Folhas & Raízes & Rizomas & Gemas \\
\hline Plantas in vitro (30 dias) & $86,64 \pm 0,55$ & $94,26 \pm 0,40$ & - & - \\
Plantas aclimatadas em C.V. ${ }^{*}$ (60 dias) & $168,22 \pm 0,77$ & $189,68 \pm 0,70$ & - & - \\
Plantas cultivadas em campo (60 dias) & $227,51 \pm 0,8$ & $183,97 \pm 0,32$ & $167,22 \pm 1,81$ & $191,03 \pm 0,29$ \\
\hline
\end{tabular}

* C.V. - Casa de Vegetação 
médios de AST que amido, sendo as gemas com teor superior entre as partes das plantas avaliadas,

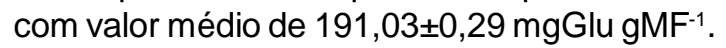

Aos 60 dias de cultivo a campo, observouse evidenciada pela formação de brotos, a quebra de dormência e diminuição nos teores de AST nas raízes, ocorrido em detrimento da necessidade imediata de energia, proveniente do metabolismo dos carboidratos que se torna mais intenso. Com novas brotações e área foliar se estabelecendo, a planta
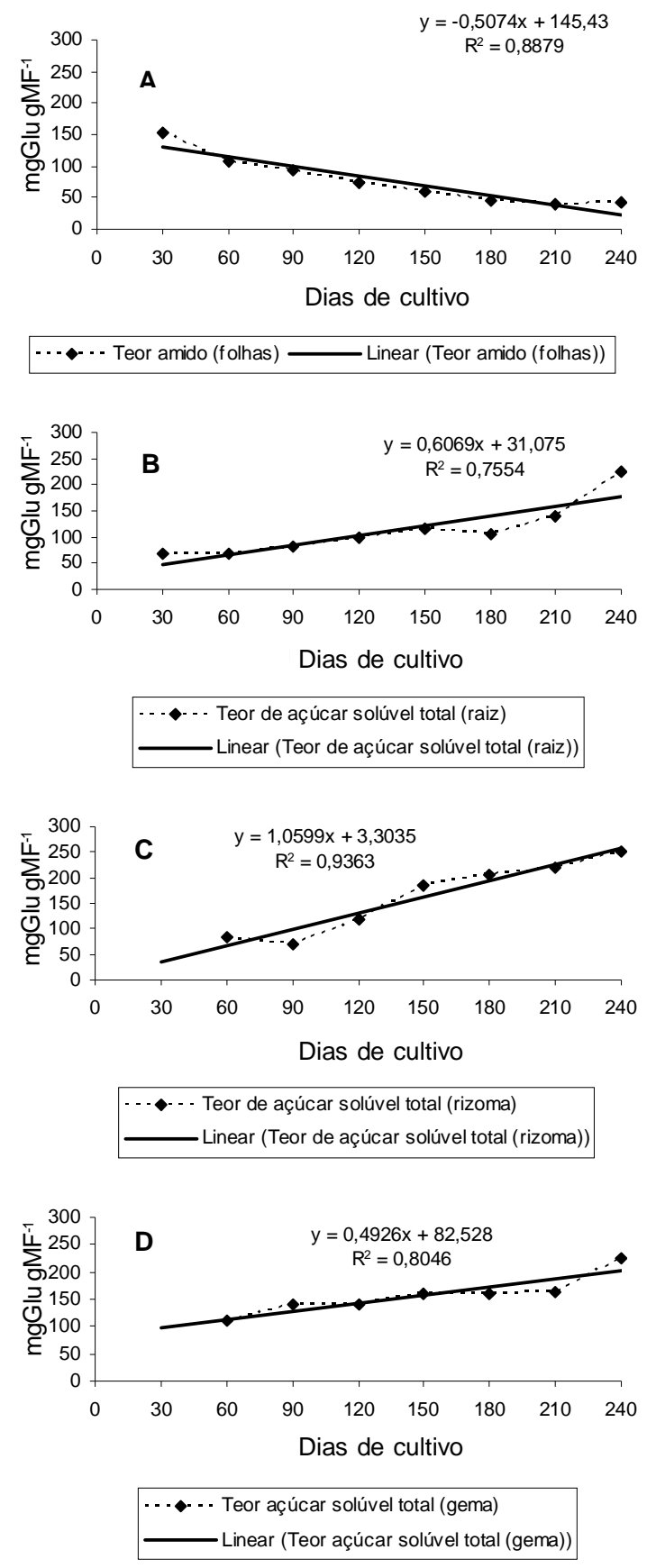

torna-se mais ativa, ao passo que o sistema radicular também se desenvolve rapidamente, havendo a necessidade de energia e esqueletos de carbono para a formação de novas raízes. Esta energia provém fundamentalmente da energia liberada pela respiração após a oxidação dos carboidratos (Borba et al., 2005).

\section{Segundo ciclo de cultivo}

No segundo ciclo de cultivo foram analisados os teores de açúcares solúveis totais e de reserva na
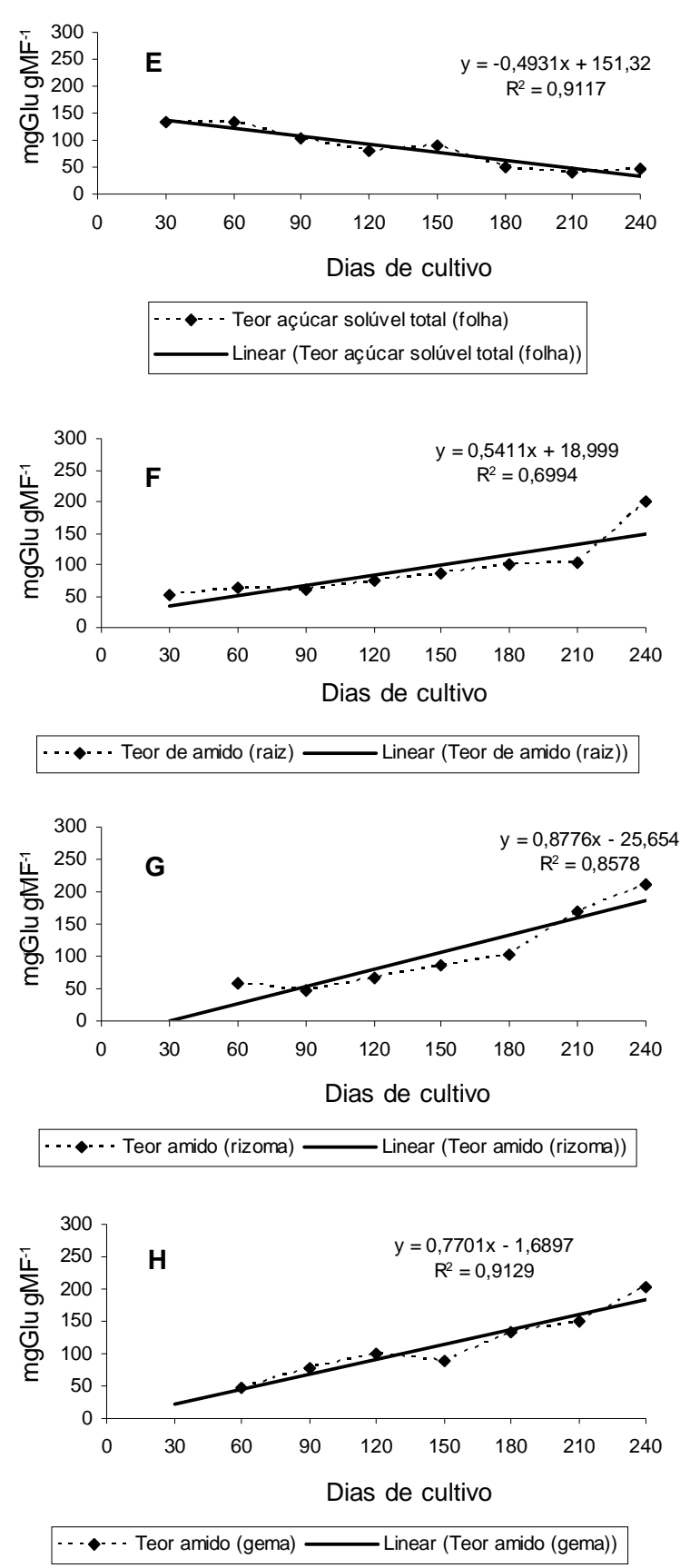

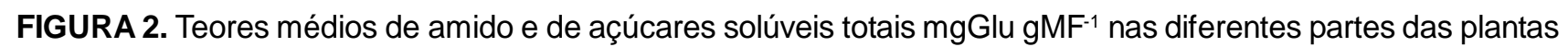
de gengibre aclimatadas em casa de vegetação dos 30 aos 240 dias de cultivo, sendo de amido: A) Folhas; B) Raiz; C) Rizoma; e D) Gema e de açúcares: E) Folhas; F) Raiz; G) Rizoma e H) Gema.

Rev. Bras. PI. Med., Botucatu, v.12, n.1, p.62-72, 2010. 
aclimatação em casa de vegetação dos 30 aos 240 dias de cultivo. No desenvolvimento das mudas observou-se aumento nos teores médios de amido nos rizomas, gemas e raízes, cujos valores podem ser observados na Figuras 2 - B, C e D) e um declínio nos teores médios nas folhas (Figura 2 - A), com uma diminuição gradativa os 240 dias de cultivo, provavelmente em detrimento da perda da parte aérea que teve o início aos 240 dias de cultivo.

O gengibre é planta perene que apresenta rizoma, o qual desempenha mais de uma função nas diferentes fases do ciclo de vida da planta (Arimura, 2002). Segundo Kerbauy (2004), rizomas são órgãos de reserva, e a parte aérea senesce ao final do período anual de crescimento, permanecendo apenas o órgão subterrâneo espessado, sendo que após um período de dormência variável, esses órgãos podem rebrotar através do desenvolvimento de gemas, utilizando reservas acumuladas e assegurando novo ciclo de desenvolvimento.

Os rizomas são essenciais para proteção das gemas nas condições desfavoráveis, sendo que fatores ambientais e endógenos podem controlar esse processo. Assim, os rizomas de gengibre funcionam como órgãos de reserva e, durante a queda das folhas e início do rebrotamento, esta reserva é translocada para os locais de intensa atividade metabólica, onde se diferenciam novos brotos, folhas e raízes.

Segundo Larcher (2000), há declínio no teor de carboidratos de reserva na base do caule e nas raízes, logo após a remoção ou queda da parte aérea. O mesmo autor ainda diz que este declínio prossegue até que haja formação de nova área foliar, suficiente para a produção de novos carboidratos, em quantidades superiores àquelas utilizadas exclusivamente para manutenção metabólica de respiração e crescimento. Entretanto, neste trabalho, o teor de AST as folhas apresentaram-se altos no período inicial, com declínio ao longo do desenvolvimento em casa de vegetação. O oposto foi verificado para as raízes, rizoma e gemas, cujos valores aumentaram ao longo dos dias de cultivo (Figura 2).

Os resultados em relação ao declínio dos teores médios de AST e de reserva observados ao longo dos dias de cultivo corroboram com o que foi relatado por Machado et al. (1989), que avaliaram variações nos teores de amido e de açúcar em folhas de cacau. Os autores verificaram menor teor de amido em detrimento da menor eficiência das folhas mais velhas, tanto em termos de fotossíntese, como de exportação de fotoassimilados. Os mesmos autores mostraram ainda, que grande porcentagem do amido foliar proveniente da fotossíntese estava acumulado na folha.

Diversos autores dividem o ciclo de desenvolvimento da cultura da batata em três fases:
(1) da emergência da tuberização, (2) do início da tuberização a senescência e (3) do início da senescência a colheita (Lopes \& Buso, 1997; Kooman et al., 1996; Paula et al., 2005). Estas fases podem ser utilizadas como modelo também para o gengibre, tendo em vista que se trata de uma planta perene que apresenta rizomas. Segundo os mesmos autores, a fase do início da tuberização ao início da senescência, os produtos da fotossíntese são usados para o crescimento dos estolões, folhas, início da formação e crescimento dos tubérculos e os açúcares produzidos pela fotossíntese são convertidos em amido e armazenados nos tubérculos. Da fase do início da tuberização à colheita, as reservas da parte aérea e os assimilados são direcionados para os tubérculos, e o amido armazenado durante o período de tuberização será utilizado no crescimento e desenvolvimento da planta.

\section{CONCLUSÃO}

A obtenção de mudas de gengibre pelo método in vitro mostra-se bastante promissora na produção de mudas isentas de patógenos.

O método de aclimatação proposto para as mudas de gengibre é viável, visto que a manutenção das mudas em casa de vegetação por período maior proporcionou $100 \%$ de sobrevivência. A composição do substrato utilizado (areia, plantmax e casca de arroz carbonizada) e a manutenção em casa de vegetação auxiliaram nos índices de sobrevivência das mudas de gengibre.

Apesar de alguns autores considerarem a possibilidade de estabelecimento de mudas micropropagadas diretamente no campo, recomendase período de aclimatação até que haja mais estudos sobre isso, tendo em vista que o estabelecimento direto no campo pode proporcionar maior vulnerabilidade das mudas, e a porcentagens observadas nestas não são muito distintas das que passam pelo período de aclimatação.

Os elevados teores de AST e de reserva obtidos nas primeiras fases de cultivo mostraram a necessidade de período de aclimatação para garantir maior sobrevivência das plantas e garantir que realizem a alocação de reservas de melhor forma. Este período de aclimatação permitiu que as plantas apresentassem características que permitiram melhor adaptação, menor vulnerabilidade e, consequentemente melhor desempenho no campo.

\section{AGRADECIMENTO}

Programa Pibic/FURB pela conceção da bolsa ao primeiro autor e à FAPESC pelo fomento. 


\section{REFERÊNCIA}

ALMEIDA, J.A.S.; PEREIRA, M.F.D.A. Efeito da temperatura e do teor de umidade na iniciação e desenvolvimento do rizoma de Kohleria eriantha (Benth.) Hanst. (Gesneriaceae). Acta Botanica Brasilica, v.18, n.4, p.863-9, 2004.

ARIMURA, C.T. et al. Interação ANA x BAP no desenvolvimento in vitro de gengibre. Acta Horticulture, v.569, p.289-91, 2002.

BABU K.N.; SAMASUDEEN K.; RATNAMBAI M.J. In vitro plant regeneration from leaf derived callus in ginger (Zingiber officinalle Rosc.). Plant Cell Tissue Organ Culture, v.29, p.71-4, 1992.

BHAGYALAKSHMI, C.; SINGH, N.S. Meristem culture and micropropagation of a variety of ginger (Zingiber officinalle R.) with a high yield of oleoresis. Journal of Horticultural Science, v.63, p.321-7, 1988.

BORBA, M.R.C.; SCARPARE FILHO, J.A.; KLUGE, A. Teores de carboidratos em pessegueiros submetidos a diferentes intensidades de poda verde em clima tropical. Revista de Fruticultura, v.27, n.1, p.68-72, 2005. CALVETE, E.O. Concentração de sacarose in vitro e seleção de substratos para aclimatização ex vitro de morangueiro cv campinas (Fragaria ananassa Duch.). 1998. 108p. Tese (Doutorado) - Universidade Federal do Rio Grande do Sul. Porto Alegre.

CAMPOSTRINI, E.; OTONI, W.C. Aclimatação de plantas: abordagens recentes. ABCTP Notícias, n.25, 1996.

CHAVES-FILHO, J.T.; STACCIARINI-SERAPHIN, E. Alteração no potencial osmótico e teor de carboidratos de carboidratos solúveis em plantas jovens de lobeira (Solanum lycocarpum St.-Hil.) em resposta ao estresse hídrico. Revista Brasileira Botânica, v.24, n.2, p.199-204, 2001

COSTA, E. Avaliação da produção de alface em função dos parâmetros climáticos em casas de vegetação com sistema hidropônico nos períodos de outono e inverno. 2001. 144p. Dissertação (Mestrado) Faculdade de Engenharia Agrícola, Universidade Estadual de Campinas, Campinas.

COUTINHO, M.; CARVALHO, E. Caracterização das propriedades de alguns substratos para propagação de mudas. Bragantia, v.14, n.1, p.67-76, 1983.

DAVIES, H.V. Sugar metabolism in stolon tips of potato during early tuberisation. Zeitschrift Pflanzenphysiology, v.113, p.77-81, 1984.

DEBIASI, C.; FELTRIN, F.; MICHELUZZI, F.C. Micropropagação de gengibre (Zingiber officinalle). Revista Brasileira de Agrociência, v.10, n.1, p.65-70, 2004.

DEDOV, V.N. et al. Gingerols: a novel class of vanilloid receptor (VR1) agonists. British Journal of Pharmacology, v.137, n.6, p.793-8, 2002.

DUBOIS, M. et al. Colorimetric method for determination of sugars and related substances. Analytical Chemistry, v.28, p.350-5, 1956.

GIRARDI, C.G.; DEBIASI, C.; PESCADOR, R. Aclimatização e desenvolvimento em campo de gengibre advindos de mudas micropropagadas e tipo convencional. Revista Scientia Agraria, v.8, n.2, p.205-11, 2007.

GRATTAPAGLIA, D.; MACHADO, M.A. Micropropagação. In: TORRES, A.C.; CALDAS, L.S. (Eds.). Técnicas e aplicações da cultura de tecidos de plantas. Brasília: Embrapa-CNPH, 1990. p.99-169.

HIDALGO, L. Tratado de viticultura general. Madrid: Ediciones Mundi-Prensa, 1993. 983p.

HOFFMANN, A. Aclimatação de mudas produzidas in vitro e in vivo. Informe Agropecuário, v.23, n.216, p.21-4, 2002.

HOFFMANN, A. et al. Fruticultura comercial: propagação de plantas frutíferas. Lavras: UFLA/FAEPE, 1996. 319p. HOSOKI, T.; SAGAWA, Y. Clonal propagation of ginger (Zingiber officinalle Rosc.) through tissue culture. Horticulture Science, v.12, p.451-2, 1997.

KÄMPF, A.N. Produção comercial de mudas ornamentais. Guaíba: Agropecuária, 2000. 54p.

KERBAUY, G.B. Fisiologia vegetal. Rio de Janeiro: Guanabara Koogan, 2004. p.452.

KHATUN, A.; NASRIN, S.; HOSSAIN, M.T. Large scale multiplication of ginger (Zingiber Officinale Rosc.) from shoot-tip culture. OnLine Journal of Biological Sciences, v.3, n.1, p.59-64, 2003.

KRAMER, P.J.; BOYER, J.S. Water relations of plants and soils. San Diego: Academic Press, 1995. 495p.

LARCHER, W. Ecofisiologia vegetal. São Carlos: Rima, 2000. 531p.

LEON, P.; SHEEN, J. Sugar and hormone connections. Trends Plant Science, v.8, n.3, p.110-6, 2003.

LEWIS, D.H. Storage carbohydrates in vascular plants: distribution, physiology and metabolism. London: Cambridge University, 1984. 284p.

LOPES, C.A.; BUSO, J.A. Cultivo da batata (Solanum tuberosum L.). Embrapa Hortaliças. Brasília : Embrapa Hortaliças, 1997. 36p.

MACHADO, R.C.R.; MÜLLER, M.W.; BARRETO, W.S. Variações diurnas no teor de amido e de açúcar solúvel em folhas de cacau (Theobroma cacao L.). Revista Brasileira de Fisiologia Vegetal, v.1, n.2, p.163-7, 1989. MCCREADY, R.M. et al. Determination of starch and amylase in vegetables application to peas. Analytical Chemistry, v.22, p.1156-8, 1950.

MERCIER, H.; KERBAUY, G.B. Microprogation of ornamental bromeliads. In: BAJAJ, Y.P.S. (Org.). Biotechnology in Agriculture and Forestry. Berlin, v.40, p.43-57,1997.

MÜLLER-RÖBER B.; SONNEWALD U.; WILLMITZER L. Inhibition of the ADP-glucose pyrophosphorylase in transgenic potatoes leads to sugar-storing tubers and influences tuber formation and expression of tuber storage protein genes. The Embo Journal, v.11, p.122938, 1992.

PASTORINI, L.H. et al. Production and non-structural carbohydrates content in potato tubers obtained in two planting times. Horticultura Brasileira, v.21, n.4, p.6605, 2003.

PEREIRA, J.E.S.; FORTES, G.R.L. Produção de mudas pré-básicas de batata por estaquia a partir de plantas micropropagadas. Horticultura Brasileira, v.22, n.2, p.185-91, 2004.

PEREIRA, J.E.S.; FORTES, G.R.L.; SILVA, J.B. Efeito da aplicação de baixa temperatura em plantas de macieira sobre o crescimento durante a aclimatização. Pesquisa Agropecuária Brasileira, v.36, n.1, p.89-95, 2001.

POLLOCK, C.G.; JONES, T. Seasonal patterns of fructan metabolism in forage grasses. New Phytologist, v.83, 
p.8-15, 1979

POSPISILOVÁ, J. et al. Acclimatization of micropropagated plantes to ex vitro conditions. Biologia Plantarum, v.42, n.4, p.481-97, 1999

ROSS-KARSTENS, G.S.; EBERT, G.; LUDDERS, P. Influence of in vitro growth conditions on stomatal density, index and aperture of grape, coffee and banana plantlets. Plant Tissue Culture and Biotechnology, v.4, p.21-7, 1998. SAMSUDEEN, K. et al. Plant regeneration from anther derived callus cultures of ginger (Zingiber officinale Rosc.) The Journal of Horticultural Science and Biotechnology, v.75, n.4, p.447-50, 2000.

SCHMITZ, J.A.K.; SOUZA, P.V.D.; KAMPF, A.N. Propriedades químicas e físicas de substratos de origem mineral e orgânica para o cultivo de mudas em recipientes. Ciência Rural, v.32, p.937-44, 2002.

SCIUTTI, R.; MORINI, S. Effect of relative humidity in vitro culture on some growth characteristics of a plum rootstock during shoot proliferation and rooting and on plantlet survival. Advances in Horticultural Science, v.7, p.153-6, 1993.

SMITH, A.M. et al. Starch mobilization in leaves. Journal of Experimental Botany, v.54, p.577-83, 2001.

TAIZ, L.; ZEIGER, E. Fisiologia vegetal. 3.ed. Porto Alegre:
Artmed, 2004. 719p.

TJADEN, J. et al. Altered plastidic ATP/ADPtransporter activity influences potato (Solanum tuberosum L.) tuber morphology, yield and composition of tuber starch. The Plant Journal, v.16, n.5, p.531-40, 1998.

VAZ, A.P.A.; KERBAUY, G.B.; FIGUEIREDO-RIBEIRO, R.C.L. Changes in soluble carbohydrates and starch partitioning during vegetative bud formation from root tips of Catasetum fimbriatum (Orchidaceae). Plant Cell, Tissue and Organ Culture, v.54, p.105-11, 1998.

WARDLE, K.; DOBBS, E.B.; SHORT, K.C. In vitro acclimatization of aseptically cultured lantlets to humidity. Journal of the American Society for Horticultural Science, v.108, n.3, p.386-9, 1983.

WARDLE, K.; QUINIAN, A.; SIMPKIS, I. Abscisic acid and the regulation of water loss in plantlets of Brassica oleraceae L. var. Botrytis regenerated through apical meristem culture. Annals of Botany, v.43, p.745-52, 1979. WILSON, S.B. et al. Responses of broccoli seedlings to light quality during low-temperature storage in vitro II. Sugar content and photosynthetic efficiency. Horticulture Science, v.33, p.1258-61, 1998.

ZEEMAN, S.C.; SMITH, S.M.; SMITH, A.M. The breakdown of starch in leaves. New Phytologist. p.1-15, 2004. 